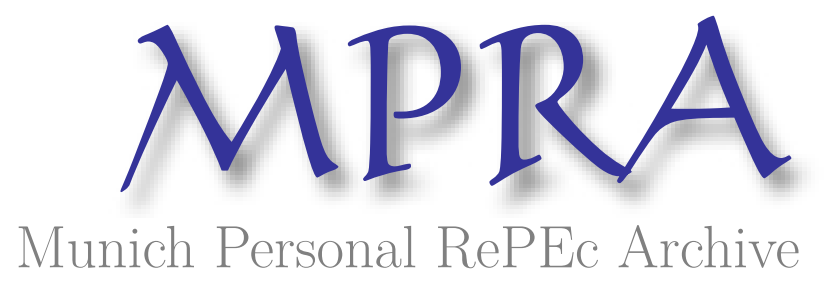

\title{
An economic assessment of the Kyoto Protocol using a global model based on the marginal abatement costs of 12 regions
}

Zhang, ZhongXiang

East-West Center

November 2001

Online at https://mpra.ub.uni-muenchen.de/13148/

MPRA Paper No. 13148, posted 04 Feb 2009 00:26 UTC 


\title{
An Economic Assessment of the Kyoto Protocol Using a Global Model Based on the Marginal Abatement Costs of 12 Regions
}

\section{ZhongXiang Zhang}

Research Program

East-West Center

1601 East-West Road

Honolulu, HI 96848-1601, USA

Tel: +1-808-944-7265, Fax: +1-808 944-7298

ZhangZ@EastWestCenter.org

\begin{abstract}
Summary:
The Kyoto Protocol incorporates emissions trading, joint implementation and the clean development mechanism to help Annex 1 countries to meet their Kyoto targets at a lower overall cost. Using a global model based on the marginal abatement costs of 12 countries and regions, this paper estimates the contributions of the three Kyoto flexibility mechanisms to meet the total greenhouse gas emissions reductions required of Annex 1 countries under the three trading scenarios respectively. Our results clearly demonstrate that the fewer the restrictions on the use of flexibility mechanisms the gains from their use are greater. The gains are unevenly distributed, however, with Annex 1 countries that have the highest autarkic marginal abatement costs tending to benefit the most. Our results also indicate that restrictions on the use of flexibility mechanisms not only reduce potential of the Annex 1 countries' efficiency gains, but also are not beneficial to developing countries because they restrict the total financial flows to developing countries under the clean development mechanism. JEL classifications: Q28; Q25; Q48; Q43
\end{abstract}

Keywords: Marginal abatement costs, Emissions trading, Clean development mechanism, Joint implementation, Kyoto Protocol, Greenhouse gases. 


\section{Introduction}

The Kyoto Protocol to the United Nations Framework Convention on Climate Change (UNFCCC), agreed in December 1997, Kyoto, is the first international environmental agreement that sets legally binding emissions targets for a basket of six greenhouse gases and timetables for Annex 1 countries (i.e., the OECD countries and countries with economies in transition). Together, Annex 1 countries must reduce their emissions of six greenhouse gases by $5.2 \%$ below 1990 levels over the commitment period 2008-2012 (UNFCCC, 1997). Reflecting the underlying principle of the UNFCCC, which states "policies and measures to deal with climate change should be cost-effective so as to ensure global benefits at the lowest possible cost", the Kyoto Protocol incorporates a variety of provisions for flexibility mechanisms through which the costs of abating emissions can be lowered. Article 6 authorizes the transfer or acquisition of "emission reduction units" from joint implementation (JI) projects among Annex 1 Parties. Article 12 establishes the so-called "clean development mechanism" (CDM). Through the mechanism, Annex 1 countries will be able to obtain the certified emission reductions from clean development projects jointly implemented with non-Annex 1 countries (i.e., developing countries), and use them to count towards meeting their commitments under the Kyoto Protocol. In addition to the two project-based mechanisms, the Kyoto Protocol accepts the concept of emissions trading in principle, under which one Annex B (an annex to the Kyoto Protocol that lists the quantified emission limitation or reduction commitment per Party) country or its sub-national entities would be allowed to purchase the rights to emit greenhouse gases (GHG) from other Annex B countries or their regulated entities that are able to cut GHG emissions below their assigned amounts or their targets. Currently, international climate change negotiations are finalizing the rules, procedures and institutions needed to make these flexibility mechanisms fully operational.

To what extent Annex 1 countries' compliance costs can be lowered depends on the extent to which the flexibility mechanisms will be allowed to contribute to meet their Kyoto targets. Under the Kyoto Protocol, each of the Articles defining the three flexibility mechanisms carries wording that the use of the mechanism must be supplemental to domestic actions. Whether the supplementarity clauses will be translated into a concrete ceiling, and if so, how should a concrete ceiling on the use of the three flexible mechanisms be defined remain to be determined. At the June 1999 Sessions of the Subsidiary Bodies of the UNFCCC, the EU (European Union, 1999) has tabled a proposal for concrete ceilings on the use of flexibility mechanisms. The EU proposal calls for the limits on both buying countries and selling countries. For a buying country, the maximum purchase for GHG emission reduction units via all three flexible mechanisms can not exceed the higher of the following two alternatives: 
(1) $5 \%$ of $\{$ (its base year emissions multiplied by $5+$ its assigned amount) $/ 2\}$;

(2) $50 \%$ of the difference between its annual actual emissions in any year between 1994 and 2002, multiplied by 5, and its assigned amount.

The EU proposal is based on quantities already agreed upon or emissions that will be observed before the proposed restriction becomes applicable (Ellerman and Wing, 2000). The difference between the two alternatives is that the first is based mainly on the Kyoto Protocol's quantified emission limitation or reduction commitments, whereas the second takes the actual emission reduction efforts of buying countries as its basis. One reason behind the two alternatives is that industrialized countries whose emissions are already very high on a per capita basis should take the lead in reducing their own emissions so that developing countries are encouraged to follow suit and take on emissions commits at a later date. Another reason has been to urge Annex 1 countries to stimulate technical innovation domestically by raising marginal abatement costs of buying countries, although it is unclear to what extent a stimulus of increased technical innovation in buying countries would remain. Motivated by alleviating the concern about hot air, the EU proposal also sets the rule for a selling country. Similar to the first alternative for a buying country, the EU proposal specifies that the maximum allowed sale for GHG emission reduction units via all three flexible mechanisms can not exceed the amount calculated by: $5 \%$ of \{ (its base year emissions multiplied by $5+$ its assigned amount)/2\}, referred to hereafter as Alternative 1 . This proposed restriction on transfers provides an indirect way of implementing supplementarity since the higher market price as a result of the restriction on the amount of hot air for sale restricts the acquisitions from what would otherwise have occurred.

Under the EU proposal, "however, the ceiling on net acquisitions and on net transfers can be increased to the extent that an Annex B Party achieves emission reductions larger than the relevant ceiling in the commitment period through domestic action undertaken after 1993, if demonstrated by the Party in a verifiable manner and subject to the expert review process to be developed under Article 8 of the Kyoto Protocol." (European Union, 1999). This is the so-called however clause. It allows an importing (exporting) country to purchase (sell) more than the amount defined by the above alternatives if verifiable domestic abatement by the importing (exporting) country can be demonstrated. Thus, the however clause effectively raises the importing ceiling and allows an importing country to purchase emission reductions from abroad up to $50 \%$ of the emission reduction requirement, provided that the country can verify a similar volume of domestic abatement undertaken after 1993.

Given the emissions reductions required of Annex 1 countries, part of the needed reductions will take place domestically, whereas the rest will come from emissions trading and JI with other Annex 1 countries, and acquisitions of the certified CDM credits from non-Annex 1 countries. Using a global model based on marginal 
abatement costs of 12 countries and regions, this paper aims to examine the implications of the differing extent of use of these flexibility mechanisms for both Annex 1 countries and non-Annex 1 countries as well as for the market price of permits under the no limits scenario, under the EU ceilings with the however clause scenario, and under the no hot air scenario. Section 2 describes the 12region's marginal abatement cost-based model used in determining the division of abatement actions at home and abroad. Section 3 discusses the data used. Section 4 presents the results. Finally, Section 5 draws up the main conclusions.

In writing the paper, we have taken a balanced approach combining the calculations with policy analysis in order to put the numbers into perspective and thus facilitate the understanding of what the numbers say. Wherever necessary we have compared our estimates with those from a variety of economic modelling studies. Although not aimed to provide a completely rigorous explanation for the differences between these estimates, such a comparison will indicate the range of such estimates and identify the sources of the differences, thus providing the broad perspective on the issues examined.

\section{The Global Model Based on Marginal Abatement Costs of 12 Countries and Regions}

Given the emissions reductions required of Annex 1 countries, part of the needed reductions will take place domestically, whereas the rest will come from emissions trading and JI with other Annex 1 countries, and acquisitions of the certified CDM credits from non-Annex 1 countries. The relative differential between the marginal cost of domestic abatement and the international price of emissions permits would apportion the total emissions reductions into domestic reductions and the demand for GHG offsets. Thus, in order to divide up abatement actions at home and abroad, we need to determine the marginal abatement costs for all the countries. Because it is a daunting task to estimate the marginal abatement cost for each individual country, we do so at a regional level. We divide the world into twelve regions. The acronyms for the twelve regions are given in Table 1 . The first six regions are Annex 1 regions, whereas the other six are non-Annex 1 regions whose emissions are unconstrained under the Kyoto Protocol. In defining these regions, we have attempted to employ the minimal level of disaggregation necessary for the purpose of this study. 
Table 1: Definitions of Countries and Regions.

\begin{tabular}{ll}
\hline Annex 1 countries and regions & Non-Annex 1 countries and regions \\
\hline 1. US: United States & 7. EEX: Energy Exporting Countries \\
2. JP: Japan & 8. CN: China \\
3. EU: European Union & 9. IN: India \\
4. OOE: Other OECD Countries & 10. DAE: Dynamic Asian Economies \\
5. EE: Eastern Europe & 11. BR: Brazil \\
6. FSU: Former Soviet Union & 12. ROW: Rest of the World \\
\hline
\end{tabular}

Now let us describe the model for determining the division of abatement actions at home and abroad. To start with, we assume that the marginal abatement cost function for region $i$ is of the quadratic form:

$$
M C A_{i}=a_{i} Q_{i}^{2}+b_{i} Q_{i}
$$

where $M C A_{i}$ is the marginal cost of domestic abatement for region $i, Q_{i}$ is the amount of greenhouse gas abatement undertaken domestically in million tons of carbon, and $a_{i}$ and $b_{i}$ are coefficients. By integration, the total cost of domestic abatement, $T C D_{i}$, is:

$$
T C D_{i}=\int_{0}^{Q_{i}}\left(a_{i} q_{i}^{2}+b_{i} q_{i}\right) d q_{i}=1 / 3 \times a_{i} Q_{i}^{3}+1 / 2 \times b_{i} Q_{i}^{2} \text { for every } i .
$$

Denoting the total emissions reductions required of the Kyoto-constrained Annex 1 region $i$ by $D_{i}$ and the amount of hot air that is allocated to region $i$ by $H_{i}$, the total autarkic abatement cost, that is, the total abatement cost in the absence of emissions trading (i.e., in the no trading case), $T C A_{i}$, is calculated as

$$
\begin{aligned}
& T C A_{i}=\int_{0}^{D_{i}-H_{i}}\left(a_{i} q_{i}^{2}+b_{i} q_{i}\right) d q_{i}=1 / 3 \times a_{i}\left(D_{i}-H_{i}\right)^{3}+1 / 2 \times b_{i}\left(D_{i}-H_{i}\right)^{2} \\
& \text { for } i=U S, J P, E U, O O E, E E .
\end{aligned}
$$

Emissions trading helps a region with high autarkic marginal cost to lower its compliance cost by avoiding the undertaking of more costly domestic actions. In this case, the region undertakes domestic abatement $Q_{i}\left(Q_{i}<D_{i}\right)$ at the marginal cost

$$
a_{i} Q_{i}^{2}+b_{i} Q_{i}=M C A_{i} \text { for } i=U S, J P, E U, O O E, E E,
$$

and meets the remaining demand $\left(D_{i}-Q_{i}-H_{i}\right)$ via purchasing the "right to emit" at the international price $p$. So, the total remaining demand of all purchasing regions, $T D$, is: 
$T D=\sum_{i}\left(D_{i}-Q_{i}-H_{i}\right) \quad i=U S, J P, E U, O O E, E E$.

Measured as percentages of the total abatement costs in the absence of emissions trading, the reductions in abatement costs for purchasing region $i$ is:

$$
G_{i}=\frac{T C A_{i}-\left(T C D_{i}+p\left(D_{i}-Q_{i}-H_{i}\right)\right)}{T C A_{i}} \quad i=U S, J P, E U, O O E, E E
$$

where $G_{i}$ is the gains from emissions trading for purchasing region $i$. On the other hand, for the Kyoto-unconstrained region with lower marginal cost, emissions trading provides an incentive for it to undertake otherwise no domestic abatement actions and sell the permits generated to those higher cost regions at the international price $p$

$$
a_{i} Q_{i}^{2}+b_{i} Q_{i}=p \quad \text { for } i=F S U, E E X, C N, I N, D A E, B R, R O W .
$$

Thus, the total amount of emissions permits available for sale, $T S$, are:

$$
T S=\sum_{i} Q_{i} \quad i=F S U, E E X, C N, I N, D A E, B R, R O W,
$$

of which, the value of the total non-Annex 1 countries' sales for permits to the Annex 1 regions, that is, the value of the CDM market, $V C D M$, is:

$$
V C D M=\sum_{i} p Q_{i} \quad i=E E X, C N, I N, D A E, B R, R O W .
$$

Subtracting their own abatement costs, the net value of the CDM market, or the net gain of non-Annex 1 regions, $N C D M$, is derived as

$$
N C D M=\sum_{i}\left(p Q_{i}-T C D_{i}\right) \quad i=E E X, C N, I N, D A E, B R, R O W .
$$

At the equilibrium, the total amount of demand for emissions permits are equal to the total supply so that we have

$$
\sum_{i} H_{i}+T S=T D \quad i=U S, J P, E U, O O E, E E, F S U .
$$

This completes the summarized description of the general model. When it is used to examine the following cases, some specific settings are involved. 
- Case A. No Limits Scenario

Even if no limits are imposed on the use of flexibility mechanisms, it is still in the interest of a purchasing country to abate its own emissions up to the point where the marginal cost of doing so is equal to the prevailing price of permits. Thus, Eq. (3) merges with Eq. (6) so that we have

$$
a_{i} Q_{i}^{2}+b_{i} Q_{i}=M C A_{i}=p \quad \text { for every } i
$$

This implies that the marginal cost of domestic abatement for each region is the same and that there is no distinction between the international price and domestic prices.

\section{- Case B. Supplementarity Restrictions Scenarios}

When a uniform formula defining the restrictions on the use of flexibility mechanisms is applied to all the regions, some regions might be allowed to purchase more than needed. Put another way, it is more costly for the regions to purchase part of the allowed acquisitions than to abate them domestically. To remove the unnecessary part, we set Eq. (3) into

$$
a_{i} Q_{i}^{2}+b_{i} Q_{i}=M C A_{i} \geq p \quad \text { for } i=U S, J P, E U, O O E, E E .
$$

As a result, a region is going to purchase permits only if it becomes more costly to undertake emissions abatement on its own. By contrast, for a region that is allowed to meet part of its commitments via the purchase of emissions permits, it must rely on domestic abatement capabilities. The lesser extent it is allowed to purchase permits abroad, the higher the domestic prices, and hence the larger the distinction between the international price and domestic prices.

- Case C. No Hot Air Scenario

Under no hot air scenario, trading in hot air is not allowed. Thus, Eq. (10) becomes

$$
T S=T D .
$$




\section{Data}

To run the above model, we first need the aggregate magnitude of emissions reductions required of each Annex 1 region and the size of hot air in 2010. The former represents the amount of the mandated reductions from projected businessas-usual (BAU) emissions levels, whereas the latter represents those assigned amounts under the Kyoto Protocol that exceed anticipated emissions requirements even in the absence of any limitation. The two types of data are derived from the individual national communications (to the UNFCCC) of the following 35 Annex 1 countries with emissions targets: Australia, Austria, Belgium, Bulgaria, Canada, Czech Republic, Denmark, Estonia, Finland, France, Germany, Greece, Hungary, Iceland, Ireland, Italy, Japan, Latvia, Lithuania, Luxembourg, the Netherlands, New Zealand, Norway, Poland, Portugal, Romania, Russia Federation, Slovakia, Slovenia, Spain, Sweden, Switzerland, Ukraine, the United Kingdom, and the United States. This involves three steps. The first step is to determine GHG emissions for each Annex 1 country in the base year. The second step is to determine the Kyoto target for each Annex 1 country in 2010. The third step is to estimate baseline GHG emissions for each Annex 1 country in 2010. By adding up the amount of the mandated reductions from projected baseline emissions levels for each Annex 1 country, the aggregate magnitude of emissions reductions required of Annex 1 countries in 2010 is estimated to be 620.6 million tons of carbon (MtC) equivalent, as given in Table 2. Similarly, the size of hot air in 2010 is calculated to be $105.0 \mathrm{MtC}^{1}{ }^{1}$ See Zhang (1999) for detailed discussion on procedures and results.

Table 2: $\quad$ Annex 1 Regions' Emissions Reductions Required and the Size of Hot Air in 2010.

\begin{tabular}{lcc}
\hline Annex 1 regions & $\begin{array}{c}\text { Emissions reductions required } \\
\text { in 2010 }(\mathrm{MtC})\end{array}$ & $\begin{array}{c}\text { The size of hot air in } \\
2010(\mathrm{MtC})\end{array}$ \\
\hline United States & 423.9 & 0 \\
Japan & 71.2 & 0 \\
European Union & 40.6 & 12.7 \\
Other OECD Countries & 57.3 & 0 \\
Eastern Europe & 27.6 & 10.9 \\
Former Soviet Union & - & 81.4 \\
Annex 1 Total & 620.6 & 105.0 \\
\hline
\end{tabular}

Source: Zhang (1999).

\footnotetext{
Note that in some regions there is the co-existence of hot air and the required emissions reductions within the same region. This is simply because of the sums across countries within each of these regions. For an individual Annex 1 country, it is either required to reduce its emissions to meet the Kyoto targets or not required if it has hot air.
} 
The second set of data are the maximum allowed acquisitions and the maximum allowed transfers in 2010. Applying the two EU ceiling alternatives to each Annex 1 country, and assuming that countries would wish to use the higher allowed acquisitions in 2010, we have calculated the maximum allowed acquisitions in 2010 for those Annex 1 countries whose emissions targets in 2010 are below their projected BAU emissions (as given in Table 3) without considering the however clause. When the however clause is factored in, the above ceilings on the allowed acquisitions are relaxed up to $50 \%$ of the difference between projected baseline emissions and the Kyoto targets in 2010. Following the same procedure as one in calculating the maximum allowed acquisitions, we have calculated the maximum allowed transfers in 2010 for those Annex 1 countries whose emissions targets in 2010 are above their projected BAU emissions. See Zhang (1999) for detailed discussion on procedures and results.

Table 3: Allowed Acquisitions and Transfers of GHG Emission Reduction Units Under the Two EU Ceiling Alternatives.

\begin{tabular}{lcc}
\hline Annex 1 regions & $\begin{array}{l}\text { Maximum allowed acquisitions } \\
\text { in 2010 without considering the } \\
\text { however clause (MtC) }\end{array}$ & $\begin{array}{l}\text { Maximum allowed } \\
\text { transfers in 2010 } \\
(\mathrm{MtC})\end{array}$ \\
\hline United States & 136.8 & - \\
Japan & 31.6 & - \\
European Union & 56.4 & 10.9 \\
Other OECD Countries & 23.3 & - \\
Eastern Europe & 14.1 & 4.4 \\
Former Soviet Union & - & 54.9 \\
Annex 1 Total & 261.9 & 70.2 \\
\hline
\end{tabular}

Source: Zhang (1999).

The third set of data are coefficients of the marginal abatement cost function for each of the above twelve regions. They are taken from Ellerman and Decaux (1998) who have estimated the marginal abatement cost (at 1985 US\$ per ton of carbon) functions for the above twelve regions running the Emissions Prediction and Policy Analysis (EPPA) model under progressively stringent carbon constraints for the year 2010 and then econometricaly estimating the EPPA runs for the amount of abated carbon emissions and the corresponding marginal abatement costs. The results are given in Table 4. It can be seen that the assumed cost functions fit very well to the results from the EPPA runs because $R^{2}$ is very close to one. 
Table 4: Coefficients of the Marginal Abatement Cost Functions of the Form: $M C A_{i}=a_{i} Q_{i}^{2}+b_{i} Q_{i}$.

\begin{tabular}{lccc}
\hline Region & $a_{i}$ & $b_{i}$ & $R^{2}$ \\
\hline USA & 0.0005 & 0.0398 & 0.9923 \\
JPN & 0.0155 & 1.8160 & 0.9938 \\
EEC & 0.0024 & 0.1503 & 0.9951 \\
OOE & 0.0085 & -0.0986 & 0.9981 \\
EET & 0.0079 & 0.0486 & 0.9973 \\
FSU & 0.0023 & 0.0042 & 0.9938 \\
EEX & 0.0032 & 0.3029 & 0.9983 \\
CHN & 0.00007 & 0.0239 & 0.9992 \\
IND & 0.0015 & 0.0787 & 0.9970 \\
DAE & 0.0047 & 0.3774 & 0.9996 \\
BRA & 0.5612 & 8.4974 & 0.9997 \\
ROW & 0.0021 & 0.0805 & 0.9967 \\
\hline
\end{tabular}

Source: Ellerman and Decaux (1998).

\section{The Economic Effects of the Three Trading Schemes in 2010}

How the total emissions reductions required of Annex 1 countries will be met depends on the extent to which the flexibility mechanisms will be allowed to contribute to meet their Kyoto targets. This is the area that remains to be decided by the climate change negotiators. For the purpose of illustration, we examine three trading scenarios here.

- No limits scenario: no caps are imposed on the use of all three flexibility mechanisms so that one Annex 1 country can trade as much as it wished until it becomes more costly for the country to trade than to abate domestically;

- The EU ceilings with the however clause scenario: just as the name implies, the scenario follows the EU proposal for concrete ceilings on the use of all three flexibility mechanisms, as discussed in Section 1. For an importing country, the maximum acquisitions from all three flexibility mechanisms are allowed up to $50 \%$ of the difference between projected baseline emissions and the Kyoto targets in 2010, provided that the country can verify a similar volume of domestic abatement undertaken after 1993. We simply assume that such a verification is possible without incurring significant transaction costs. On the export side, we assume that unconstrained countries (those with hot 
air) would be limited to exporting only the amount of hot air, which is defined by the alternative 1 under the EU proposal; and

- No hot air scenario: trading in hot air is not allowed, indicating that any effectuated trading in GHG emissions must represent 'real' emissions reductions.

Under the above three scenarios, trading of emissions permits is assumed to take place globally among all the countries. But, under the Kyoto Protocol non-Annex 1 countries currently have no obligations to reduce their GHG emissions. Thus, in our modelling exercises, these countries are treated as if they agreed to constrain their emissions in such a manner that they are allocated permits equal to their projected baseline emissions. As such, non-Annex 1 countries only reduce their emissions by an amount equal to the number of permits they wish to sell. Following the definition of the certified credits from CDM projects, the amount of emissions reductions below the country-wide baseline trend is termed as the supply of the certified CDM credits from each non-Annex 1 countries. $^{2}$

\subsection{Contributions of the Kyoto Flexibility Mechanisms}

For countries whose emissions targets specified under the Kyoto Protocol are expected to exceed their anticipated emissions requirements even in the absence of any limitation, Section 3 indicates that these countries in 2010 will have surplus assigned amounts of 105.0 MtC available for sale. Because hot air is available at zero abatement cost, hot air is assumed to be used to the maximum extent allowed, except for under the no hot air scenario. This means that, of the aggregate demand of $620.6 \mathrm{MtC}$ in 2010 , hot air contributes to $105.0 \mathrm{MtC}$ under the no limits scenario, and to $70.2 \mathrm{MtC}$ under the EU ceilings with the however clause scenario. Then, the remaining demand will be met via domestic abatement actions and three flexibility mechanisms.

Inserting the aggregate magnitude of emissions reductions required and the size of hot air in 2010, the maximum allowed acquisitions and the maximum allowed transfers in 2010, and the estimated coefficients of the marginal abatement cost function for each of the above twelve regions, we solve the 12-region's marginal abatement cost-based model for determining the division of abatement actions at

2 This implies that in our modelling exercises we treat the CDM synonymously with emissions trading as many other modellers do (Weyant, 1999). In real practice, the $\mathrm{CDM}$ is a project-based mechanism. Unlike homogenous permits under emissions trading, concerns about additionality and the inherent difficulty of establishing counterfactual baselines for heterogeneous CDM projects and monitoring emissions reductions below the baselines may impose high transaction costs and thereby limit the supply of CDM credits from non-Annex 1 countries (Ellerman and Decaux, 1998; US Administration, 1998). 
home and abroad using GAMS, a widely distributed nonlinear programming package (Brooke et al, 1996).

According to our calculations, even if no limits are imposed on the use of all three flexibility mechanisms, not all the emissions reductions required of an Annex 1 country will take place abroad. This is because even if no account is taken of ancillary benefits of reducing GHG emissions, it is still in the interest of any buying country to reduce its own emissions as long as the marginal costs of doing so are lower than the prevailing prices of permits. Based on the marginal costs of domestic abatement for the twelve regions, it is estimated that a reduction of 171.7 $\mathrm{MtC}$, or $27.7 \%$ of the total needed emissions reductions in 2010 will be met through domestic actions of Annex 1 countries under the no limits scenario (see Table 5). This is broadly in line with the finding of the IPCC (1996) that reducing emissions by $20 \%$ from 1990 levels in developed countries within the next two or three decades can be achieved domestically through no-regrets options. When trading in hot air is not allowed, the international price of permits increases in comparison with the no limits scenario (see Table 6). As a result, the demand for permits abroad decreases, and more and more domestic abatement is undertaken. This is confirmed in Table 5, which indicates that a reduction of $203.5 \mathrm{MtC}$, or $32.8 \%$ of the total needed emissions reductions in 2010 will be met through domestic actions of Annex 1 countries under the no hot air scenario. Under the EU ceilings with the however clause scenario, the amount of abatement through domestic actions in 2010 is estimated to be $315.4 \mathrm{MtC}$, or $50.8 \%$ of the total emissions reductions required of Annex 1 countries in 2010. The reason why the Annex 1 countries as a whole abate slightly over $50 \%$ domestically under this EU ceiling scenario is that Eastern Europe abates $68.7 \%$ domestically (Zhang, 2001). This in turn is because its low marginal abatement cost allows it to benefit from exporting permits up to the extent that its domestic abatement cost equals the international price of permits.

Table 5: The Contributions of Three Flexibility Mechanisms Under the Three Trading Scenarios in 2010 (MtC).

\begin{tabular}{lccccc}
\hline Scenarios & $\begin{array}{c}\text { Domestic } \\
\text { actions }\end{array}$ & Hot air & $\begin{array}{c}\text { Emissions } \\
\text { trading and JI }\end{array}$ & CDM & $\begin{array}{c}\text { Total } \\
\text { supply }\end{array}$ \\
\hline No limits & 171.7 & 105.0 & 51.8 & 292.1 & 620.6 \\
$\begin{array}{l}\text { EU ceilings with } \\
\text { the however clause }\end{array}$ & 315.4 & 70.2 & 39.6 & 195.4 & 620.6 \\
$\quad$ No hot air & 203.5 & 0 & 59.6 & 357.5 & 620.6 \\
\hline
\end{tabular}

Table 5 summarizes estimates of the contributions of three flexibility mechanisms under the three trading scenarios. It can be seen that the supply of certified CDM credits in 2010 ranges from 195.4 MtC under the EU ceilings with the however clause scenario to 292.1 MtC under the no limits scenario and to 357.5 MtC under the no hot air scenario, respectively. In comparison with the no limits scenario, the 
EU ceilings with the however clause restriction would reduce the size of the CDM market by $33.1 \%$. Although such a restriction is much relaxed in terms of its impact on the size of the CDM market, in comparison with the EU ceilings without the however clause scenario under which the size of the CDM market is cut by 54.9\% (Zhang, 2001), its impact on the size of the CDM market is still very severe. Of the total emissions reductions required of Annex 1 countries in 2010, the supply of the certified CDM credits accounts for $31.5 \%$ under the EU ceilings with the however clause scenario, $47.1 \%$ under the no limits scenario, and $57.6 \%$ under the no hot air scenario, respectively.

Table 6: $\quad$ Autarkic Marginal Abatement Costs in the No Trading Case, and Domestic Prices and the International Prices of Permits in 2010 Under the Three Trading Scenarios (at 1998 US\$ per ton of carbon).

\begin{tabular}{lrrrrc}
\hline Scenarios & $\begin{array}{c}\text { United } \\
\text { States }\end{array}$ & Japan & $\begin{array}{c}\text { European } \\
\text { Union }\end{array}$ & $\begin{array}{r}\text { Other } \\
\text { OECD }\end{array}$ & $\begin{array}{c}\text { International } \\
\text { price }\end{array}$ \\
\hline No emissions trading & 160.1 & 311.8 & 9.1 & 33.4 & - \\
No limits & 9.6 & 9.6 & 9.6 & 9.6 & 9.6 \\
$\begin{array}{l}\text { EU ceilings with } \\
\text { the however clause }\end{array}$ & 46.3 & 126.4 & 6.1 & 6.2 & 5.6 \\
$\quad$ No hot air & 12.6 & 12.6 & 12.6 & 12.6 & 12.6 \\
\hline
\end{tabular}

When there are no limits imposed on the use of flexibility mechanisms, the marginal cost of domestic abatement for each region equalizes, and there is no distinction between the international price and domestic prices. Based on the model, the international price of permits in 2010 is calculated to be US\$ 9.6 per ton of carbon. This price is pushed up to US\$ 12.6 per ton when trading in hot air is not allowed. The increase in the international price is partly because any sales for permits by the former Soviet Union are generated by no cost-free abatement undertaken to earn export permits additional to the amount of hot air, and partly because preventing trading in hot air increases the OECD countries' demand for the certified CDM credits. When the supplementarity restriction as specified under the EU proposal is imposed on the acquisitions, the purchases of permits are restricted. This will push down the market price. Thus, the international price of permits is much lower under the EU ceilings with the however clause scenario than under the no limits scenario. Moreover, because no account is taken of the differences in the marginal costs of domestic abatement among the Annex 1 countries, all the countries are required to comply with the same supplementarity rule. This could lead to a distinction between the international price of permits and domestic prices of buying countries. The lesser extent it is allowed to purchase permits abroad, the higher the domestic prices, and hence the larger the distinction between the international price and domestic prices. As indicated in Table 6, because the autarkic marginal abatement cost for Japan is highest, the EU proposed restriction leads to the largest differential between the domestic price in Japan and the international price of permits. On the other hand, because the 
official projections of baseline GHG emissions in 2010 by most EU member countries are very close to their targets, the EU only needs to purchase a vey small amount of permits to meet its targets. ${ }^{3}$ As a result, the supplementarity restriction examined here on the EU is much less severe than on Japan and the US. Consequently, domestic price for the EU is very close to the international price of permits.

Because autarkic marginal abatement costs for the OECD countries excluding the EU are much higher than the market price of permits, trading can help these countries to lower their compliance costs by avoiding their undertaking of more costly domestic actions. The extent to which the compliance costs can be lowered depends on the relative differential between the autarkic marginal cost of the country in question and the international price of emissions permits. In percentage terms, the countries whose autarkic marginal costs are much higher than the market price will benefit more than those countries whose autarkic marginal costs are closer to the market price. As indicated in Table 7, because Japan and the US have the highest autarkic marginal abatement costs, the two countries benefit the most from trading both under the no limits scenario and under the no hot air scenario. Measured as percentages of the total abatement costs in the no trading case, the abatement costs of Japan and the US are cut by $93.1 \%$ and $85.2 \%$ under the no limits scenario, and $91.0 \%$ and $81.0 \%$ under the no hot air scenario, respectively. By contrast, because the autarkic marginal cost for the EU is very close to the market price, it achieves only small gains from trading under the above two scenarios. Besides, the restriction on the use of flexibility mechanisms tends to lower the gain from trading. For the OECD as a whole, the reduction in abatement costs, namely, the gain from emissions trading, decreases from $86.5 \%$ under the no limits scenario to $78.4 \%$ under the EU ceilings with the however clause scenario.

Table 7: The Reductions in the Total Abatement Costs in 2010 Under the Three Trading Scenarios (\%).

\begin{tabular}{lccccc}
\hline Scenarios & $\begin{array}{c}\text { United } \\
\text { States }\end{array}$ & Japan & $\begin{array}{c}\text { European } \\
\text { Union }\end{array}$ & $\begin{array}{c}\text { Other } \\
\text { OECD }\end{array}$ & OECD \\
\hline No limits & 85.2 & 93.1 & 0.2 & 45.3 & 86.5 \\
$\begin{array}{l}\text { EU ceilings with } \\
\text { the however clause }\end{array}$ & 79.8 & 76.5 & 16.3 & 63.9 & 78.4 \\
$\quad$ No hot air & 81.0 & 91.0 & 2.3 & 33.5 & 82.4 \\
\hline
\end{tabular}

3 The low EU baseline projections are attributable in large part to internal burden sharing of the Kyoto commitments among the member countries, having incorporated the impacts of energy policies that are currently being either implemented or negotiated in response to climate change, and to the choice of base year. See Zhang $(1999,2001)$ for detailed discussion. 


\subsection{The Size of the CDM Market and the Shares of China and India}

Multiplying the endogenously-determined, international price of permits by the supply of certified CDM credits from each non-Annex 1 country and summing over all the corresponding product, we can derive the value of the CDM market in 2010. As indicated in Table 8, our estimate ranges from US\$ 1103.4 million under the EU ceilings with the however clause scenario to US\$ 4512.8 million under the no hot air scenario. Subtracting their own abatement costs, the net value of the CDM market in 2010, or the net gain of non-Annex 1 countries is estimated to be in the range of US\$ 603.0 million under the EU ceilings with the however clause scenario to US\$2559.1 million under the no hot air scenario. The finding that the net gain of non-Annex 1 countries is highest when trading in hot air is not allowed indicates that to prevent trading in hot air, although in practice it is very difficult to distinguish real emissions reductions from hot air, is beneficial to the expanding of the CDM market as well as to the global climate. With respect to the geographical distribution of the CDM flows, because of a great deal of low-cost abatement opportunities available in the energy sectors of China and India and their sheer sizes of population, the two countries are expected to emerge as the dominant host countries of CDM projects. This is confirmed in Table 8, which shows that about three-quarters of the total CDM flows go to China and India, respectively. Because of relatively high abatement costs and relatively small size, the remaining four non-Annex 1 regions account for only $25 \%$ of the total flows channelled to developing countries through the CDM.

Table 8: $\quad$ The Value of the CDM Market and the Shares of China and India in 2010 Under the Three Trading Scenarios.

\begin{tabular}{lccc}
\hline & $\begin{array}{c}\text { No } \\
\text { limits }\end{array}$ & $\begin{array}{c}\text { EU ceilings without } \\
\text { the however clause }\end{array}$ & No hot air \\
\hline $\begin{array}{l}\text { CDM market (million US\$) } \\
\text { of which: }\end{array}$ & 2795.6 & 1103.4 & 4512.8 \\
$\quad$ China & $60.3 \%$ & $60.0 \%$ & $60.4 \%$ \\
India & $15.1 \%$ & $15.5 \%$ & $14.9 \%$ \\
& & & \\
Net CDM market (million US\$) & 1565.0 & 603.0 & 2559.1 \\
of which: & & & $60.1 \%$ \\
$\quad$ China & $59.9 \%$ & $59.6 \%$ & $15.3 \%$ \\
India & $15.5 \%$ & $16.0 \%$ & \\
\hline
\end{tabular}

Because the CDM has an important role in helping Annex 1 countries to meet their Kyoto targets at a lower overall cost, some studies have estimated the potential size of the CDM market. As indicated in Table 9, these estimates vary. Assuming the contributions from domestic abatement actions and hot air and dividing the remaining demand between emissions trading and JI among Annex 1 
countries and the CDM within non-Annex 1 countries in proportion to the estimated potential of supply, Haites (1998) estimates that the size of the CDM market in 2010 ranges from $265 \mathrm{MtC}$ under 50\% reduction from BAU emissions scenario (under which the maximum allowed acquisitions from all three flexibility mechanisms are limited to $50 \%$ of the difference between projected BAU emissions and the Kyoto targets in 2010) to $575 \mathrm{MtC}$ under the no limits scenario. The size of the market estimated by the four economic modelling studies examined ranges from $397 \mathrm{MtC}$ with the OECD GREEN model (Van der Mensbrugghe, 1998) to $723 \mathrm{MtC}$ with the EPPA model (Ellerman and Decaux, 1998). Austin et al. (1998) argue that such estimates derived from these global modelling exercises tend to overestimate CDM flows because, in practice, political limitations and transaction costs will probably keep CDM activity at the lower end of such estimates. Of the studies examined in Table 9, the estimate by Vrolijk (1999) is at the low end of the range. In absolute terms, our estimate is at the low to middle end. This is mainly because, as indicated in Table 9, our estimate of total emissions reductions required of Annex 1 countries, which is based on compilation of the national communications from 35 Annex 1 countries, is lower than those estimates from economic modelling studies. As discussed in Zhang (1999), the main reason is that the official projections of baseline GHG emissions in 2010 by most EU member countries are very close to their targets, thus leading to low demand for emissions reductions. In percentage terms, our estimate of the contribution of the certified CDM credits is broadly in line with other estimates. Our upper bound estimate comes from the no hot air scenario. If the supply of hot air is included as other estimates from economic modelling studies do, then our upper bound estimate will come down to $47.1 \%$ under the no limits scenario.

Table 9: $\quad$ Estimates of the Size of the CDM Market in 2010.

\begin{tabular}{lccr}
\hline & $\begin{array}{c}\text { Size of the CDM } \\
\text { market (MtC) }\end{array}$ & $\begin{array}{c}\text { Total emissions reductions } \\
\text { required of Annex 1 } \\
\text { countries (MtC) }\end{array}$ & $\begin{array}{c}\text { Contribution of } \\
\text { the CDM (\%) }\end{array}$ \\
\hline EPPA & 723 & 1312 & 55 \\
Haites & $265-575$ & 1000 & $27-58$ \\
G-Cubed & 495 & 1102 & 45 \\
GREEN & 397 & 1298 & 31 \\
SGM & 454 & 1053 & 43 \\
Vrolijk & $67-141$ & 669 & $10-21$ \\
Our projection & $195-358$ & 621 & $31-58$ \\
\hline
\end{tabular}

Sources: Edmonds et al. (1998); Ellerman and Decaux (1998); Haites (1998); McKibbin et al. (1999); Van der Mensbrugghe (1998); Vrolijk (1999); Zhang (2001).

Can the CDM actually produce the amount of certified credits as we estimate here? This is not that easy to answer, but experience with activities implemented jointly (AIJ) might give us some indications. The first Conference of the Parties to 
the UNFCCC in Berlin in April 1995 endorsed a pilot AIJ phase. During the AIJ pilot phase, emission reductions achieved are not allowed to be credited to current national commitments of investor countries under the UNFCCC. By the time (30 June 1998) of the UNFCCC's second synthesis report on AIJ, 95 projects were listed as AIJ projects (UNFCCC, 1998). These projects are located in 24 host countries, with Africa hosting only one certified AIJ project. If all the projects were fully implemented and operating as designed, they would generate a combined GHG offset of 162 million tons of $\mathrm{CO}_{2}$ equivalent, namely, $44 \mathrm{MtC}$ equivalent, over an average lifetime of 16.5 years (UNFCCC, 1998). Translated into an annual GHG offset, it amounts to $2.7 \mathrm{MtC}$. By contrast, the projected contribution of the certified CDM credits implies as much as a 100-fold increase in this type of project-based activities. Although lack of adequate incentives for the private sector participation in AIJ project financing limits the role of the AIJ, to achieve such a substantial scale of increase in the quantity of emissions reductions, although not impossible, poses great institutional challenges for developing countries, given that most non-Annex 1 countries have not experienced an AIJ project within their own countries.

\section{Conclusions}

The Kyoto Protocol incorporates emissions trading, joint implementation and the clean development mechanism to help Annex 1 countries to lower the costs of meeting their Kyoto targets. To what extent their compliance costs can be lowered depends on the extent to which the flexibility mechanisms will be allowed to contribute to meet their Kyoto targets. Taking the year 2010 as representative of the first commitment period, and using a global model based on marginal abatement costs of 12 countries and regions, this paper estimates how many of the emissions reductions required of Annex 1 countries in 2010 will be met through domestic abatement actions, emissions trading and JI, and acquisitions of the certified CDM credits under the no limits scenario, under the EU ceilings with the however clause scenario, and under the no hot air scenario.

Our results suggest that, of the total emissions reductions required of Annex 1 countries in 2010, domestic actions account for $27.7 \%$ under the no limits scenario, $32.8 \%$ under the no hot air scenario, and $50.8 \%$ under the EU ceilings with the however clause scenario. The contributions of the certified CDM credits in 2010 are estimated to range from $31.5 \%$ under the EU ceilings with the however clause scenario to $47.1 \%$ under the no limits scenario and to $57.6 \%$ under the no hot air scenario. In absolute terms, the supply of the certified CDM credits in 2010 ranges from $195.4 \mathrm{MtC}$ under the EU ceilings with the however clause scenario to $292.1 \mathrm{MtC}$ under the no limits scenario and to $357.5 \mathrm{MtC}$ under the no hot air scenario, respectively. Although it is at the low to middle end of those 
estimates derived from economic modelling studies, our projected contribution of the certified CDM credits implies as much as a 100-fold increase in the type of project-based activities in comparison with an annual GHG offset through the AIJ of $2.7 \mathrm{MtC}$. No doubt, to achieve such a substantial scale of increase in the quantity of emissions reductions, although not impossible, poses great institutional challenges for developing countries. With respect to the geographical distribution of the CDM flows, we found that China and India account for about three-quarters of the total flows channelled to developing countries through the CDM.

Besides, our results clearly indicate that the use of flexibility mechanisms helps to lower the OECD countries' compliance costs by avoiding their undertaking of more costly domestic actions. However, the magnitude of reductions in compliance costs differs substantially among the OECD countries. In percentage terms, the countries whose autarkic marginal abatement costs are much higher than the market price of permits will benefit more than those countries whose autarkic marginal abatement costs are closer to the market price. Furthermore, our results demonstrate that restrictions on the use of flexibility mechanisms not only reduce potential of the Annex 1 countries' efficiency gains, but also are not beneficial to developing countries because they restrict the total financial flows to developing countries under the CDM. Thus, from the perspective of husbanding the world's limited resources, the fewer the restrictions on the use of flexibility mechanisms the gains from their use are greater.

\section{Acknowledgements}

This paper formed part of the presentations at the Asian Development Bank/United Nations Environment Programme's Workshop for Policymakers on the Institutional Design of the Kyoto Protocol Cooperative Implementation Mechanisms, UN Conference Center, Bangkok, 12-14 October 1999; the International Workshop on Enhancing GHG Mitigation through International Cooperative Mechanisms in Asia, Kanagawa, Japan, 26-27 January 2000; China-US Workshop on Economic and Environmental Modeling, Beijing, 5-6 March 2000; the $3^{\text {rd }}$ Biennial Conference of the European Society for Ecological Economics, Vienna, 3-6 May 2000; the 10th Annual Conference of the European Association of Environmental and Resource Economists, Crete, Greece, 30 June - 2 July 2000; the Joint Meeting of the Energy Modeling Forum and the International Energy Workshop, Stanford University, 20-22 June 2000; the $40^{\text {th }}$ Congress of the European Regional Science Association, Barcelona, 29 August - 1 September 2000; the Workshop on Empirical Modeling of the Economy and the Environment, Mannheim, Germany, 26-27 June 2001; and at the International Expert Meeting on Climate Change and Sustainable Development, Seoul, 6-7 September 2001; as well as at seminars at Tsinghua University, Beijing, 17 March 
2000 and East-West Center, Honolulu, 16 April 2001. The author would like to thank participants in the above Workshops and Conferences, J.R. Bhatt, A. Denny Ellerman and Adam Rose for useful discussions and comments on an earlier version of the paper. Financial support from the Asian Development Bank is gratefully acknowledged. The views expressed here are those of the author, and do not necessarily reflect the positions of the Asian Development Bank. All errors and omissions are my own.

\section{References}

Austin, D., P. Faeth, R.S. da Motta, C.E.F. Young, C. Ferraz, J. Zou, J. Li, M. Pathak and L. Srivastava (1998), Opportunities for Financing Sustainable Development via the CDM: A Discussion Draft. Presented at a Side-Event of the Fourth Conference of the Parties to the UNFCCC, 7 November, Buenos Aires.

Brooke, A., D. Kendrick and A. Meeraus (1996), GAMS Release 2.25: A User's Guide, GAMS Development Corporation, Washington, DC 20007.

Edmonds, J., C. MacCracken, R. Sands and S. Kim (1998), Unfinished Business: The Economics of the Kyoto Protocol, Pacific Northwest National Laboratory, Prepared for U.S. Department of Energy.

Ellerman, A.D. and A. Decaux (1998), Analysis of Post-Kyoto $\mathrm{CO}_{2}$ Emissions Trading Using Marginal Abatement Curves, MIT Joint Program on the Science and Policy of Global Change, Report No. 40, Massachusetts Institute of Technology.

Ellerman, A.D. and I.S. Wing (2000), Supplementarity: An Invitation to Monopsony?, MIT Joint Program on the Science and Policy of Global Change, Report No. 59, Massachusetts Institute of Technology.

European Union (1999), Community Strategy on Climate Change: Council Conclusions, No. 8346/99, 18 May, Brussels.

Haites, E. (1998), Estimate of the Potential Market for Cooperative Mechanisms 2010, Margaree Consultants Inc., Toronto, Canada.

IPCC (1996), Climate Change 1995: Economic and Social Dimensions of Climate Change, Contribution of Working Group III to the Second Assessment Report of the Intergovernmental Panel on Climate Change (IPCC), Cambridge.

McKibbin, W.J., M.T. Ross, R. Shackleton and P.J. Wilcoxen (1999), Emissions Trading, Capital Flows and the Kyoto Protocol, Presented at the Intergovernmental Panel on Climate Change Working Group III Expert Meeting on the Economic Impacts of Annex 1 Mitigation Policies on non-Annex 1 Countries, 27-28 May, The Hague.

Tulpulé, V., S. Brown, J. Lim, C. Polidano, H. Pant and B.S. Fisher (1998), An Economic Assessment of the Kyoto Protocol Using the Global Trade and Environment Model, Presented at the OECD Workshop on the Economic Modelling of Climate Change, 1718 September, Paris. 
UNFCCC (1997), Kyoto Protocol to the United Nations Framework Convention on Climate Change (UNFCCC), FCCC/CP/1997/L.7/Add.1, Bonn.

UNFCCC (1998), Review of the Implementation of Commitments and of other Provisions of the Convention. Activities Implemented Jointly: Review of Progress under the Pilot Phase (Decision 5/CP.1), Second Synthesis Report on Activities Implemented, United Nations Framework Convention on Climate Change (UNFCCC), FCCC/CP/1998/2, Bonn.

US Administration (1998), The Kyoto Protocol and the President's Policies to Address Climate Change: Administration Economic Analysis, Washington, DC.

Van der Mensbrugghe, D. (1998), A (Preliminary) Analysis of the Kyoto Protocol: Using the OECD GREEN Model, Presented at the OECD Workshop on the Economic Modelling of Climate Change, 17-18 September, Paris.

Vrolijk, C. (1999), The Potential Size of the CDM, Greenhouse Gas Emissions Trader, No. 6, UNCTAD, Geneva, pp. 2-4.

Weyant, J.P. (ed., 1999), The Cost of the Kyoto Protocol: A Multi-Model Evaluation, Energy Journal 20 (Special Issue), pp. 1-398.

Zhang, Z.X. (1999), Estimating the Size of the Potential Market for All Three Flexibility Mechanisms under the Kyoto Protocol, Report Prepared for the Asian Development Bank under Contract TA-5592-REG.

Zhang, Z.X. (2001), An Assessment of the EU Proposal for Ceilings on the Use of Kyoto Flexibility Mechanisms, Ecological Economics 37(1), pp. 53-69. 